THIRD COUNTRY EFFECT ON EXCHANGE RATE: A THEORETICAL EXPLANATION

N Keembiyahetti
Sri Lanka Journal of Economic Research Volume 9(1) December 2021 SLJER 09.01.05: pp. 89-113

Sri Lanka Forum of University Economists DOI: http://doi.org/10.4038/sljer.v9i1.157

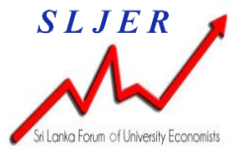

\title{
Abstract
}

This paper presents a theoretical model to explain the third country effect on bilateral exchange rate. The conventional trade theories suggest that the bilateral exchange rate in a free-floating regime is determined by the demand and supply of the two currencies concerned. It implies that all the credit items in the balance of payment forming the supply side and all the debit items in the balance of payment forming the demand side would determine the bilateral equilibrium exchange rate. The traditional two country trade models are based on the implied assumption that the key variables such as exports, imports, FDIs, and net transfers between the two countries are key determinants of the foreign exchange rate between the two currencies concerned.

This paper extends the traditional two country model into a three-country model and logically shows the possibility of variables pertaining to a third country to influence the bilateral exchange rate of the two countries concerned, which is known as the "third country effect". The "third country effect" is not a novel concept in trade literature. It has been empirically tested by many researchers on several grounds such as the third country effect on trade, the third country effect on the domestic interest rate, the third country effect on the domestic price level etc. Although almost all such studies more or less have justified empirical evidence supporting the existence of the third country effect, the transmission mechanism of the third country shocks is still not clear. This paper develops a theoretical model to demonstrate how the third country effect is transmitted to the bilateral exchange rate. This paper bridges a long-standing gap in theory and literature.

Keywords: Exchange Rate, Balance of Payment, Trade balance, Third Country Effect, Three Country Model

\section{N Keembiyahetti}

University of Ruhuna, Sri Lanka

Email: nandasiri2007@gmail.com Tel: +94 715359388 


\section{INTRODUCTION}

The exchange rate between two currencies can be affected by a shock emerging from a third country. A third country could be any country other than the two countries concerned in defining a bilateral exchange rate. Throughout this article, we use the term "third country" to refer to any country or perhaps a group of countries other than the two countries within which we define the exchange rate. It does not imply that any particular third country can influence all the bilateral exchange rates.

The discussion on the third country effect was originally opened up by Cushman (1986) investigating the effect of exchange rate uncertainty on bilateral trade related to USCanada trade. Cushman (1986) asserted the positive and significant effect of exchange rate uncertainty on US exports to Canada. More interestingly, he observed that significantly positive effect faded away when the third country effect was explicitly introduced to the model.

Among recent investigations into the third country effect, it is noteworthy to mention the contribution by Hodrick and Vassalou (2002), Nucci (2003), Marsh and MacDonald (2004), Melecky and Kingston (2007) justifying the existence of third country effects. Melecky (2008) recognized three channels through which the third country effect could be transmitted namely, domestic price level, interest rate and the output gap. Maggie and Joshi (2010) viewed the third country effect from a different angle claiming that a country's decision to form a Free Trade Agreement (FTA) with another country is likely to depend on the existing FTA with a third country. Bahmani and Xu (2012) recently found out significant short run evidence of the third country effect when the volatility of U.S. Dollar and Canadian Dollar was introduced to the trade flows between the US and China.

Most of the studies supporting the third country effect concentrate on transmission of the third country effect to the domestic interest rates via Recovered/Unrecovered Interest Rate Parity (IRP) or to the domestic price level via Exchange Rate Pass-through Effect (ERPE).

However, there is little empirical evidence and almost no theoretical explanation regarding transmission of the third country effect to the exchange rate itself. We believe that one important reason for this vacuum is that the traditional two country trade models widely used in international trade have an inherent natural tendency to ignore the third country effects.

In this paper, we attempt to develop a theoretical model to explain the third country effect on exchange rate determination under the free-floating regime. After a brief review of empirical work carried out in the third section of this paper, we rearticulate the existing standard two country exchange rate model, and thereafter in the fourth section, we upgrade it to a three-country model to incorporate the third country effect. 


\section{EMPIRICS ON THE THIRD COUNTRY EFFECT}

The third country effect has been tested in a few recent pieces of research, some of which are summarized below.

Bahmani \& Bolhassani (2014) assessed the impact of exchange rate uncertainty on the trade flows of 152 industries that trade between the United States and Canada. They wondered how the results will change if we account for the "third-country effect," especially the fluctuation of the U.S. Dollar against the currency of the third member of NAFTA, Mexico. They affirmed that, the third-country effect seems to be present in the same number of industries, in the short run as well as in the long run.

Kimberly and Mark, (2015) empirically testing the third-country effects on the exchange rate, have argued that predictive regressions for bilateral exchange rates characteristically have low explanatory power, which leaves room for an omitted variables interpretation. They tested whether these omitted variables are from third countries. When third-country macro factors are added to bilateral exchange rate regressions, they found a significant increase in the adjusted R2. A three-country exchange rate model illustrates potential channels for third-country spill overs to affect the bilateral rate in their study. In the first part of their study, using data from 26 countries, they empirically tested the implications of when the two countries differ in monetary policy and price stickiness. In the second part, with Monte Carlo experiments they studied the impact of the third country fundamentals on the bilateral exchange rate and found out that the explanatory power is increased when omitted third country variables are added to the model.

Bahmani \& Aftab (2018) using monthly data from 54 Malaysian industries that export to the US and 63 Malaysian industries that import from the US, proved that the impact of exchange rate volatility declines after the inclusion of the third-country effect when using a linear analysis. However, when tested for asymmetric effects of exchange rate volatility including nonlinear adjustment of volatility measures, the findings were more favourable to both the exchange rate volatility and the third-country effect. Therefore, these scholars proposed that consideration must be given not to just asymmetric effects of exchange rate volatility but also to asymmetric effects of the third-country effect in examining exchange rate volatility effect on trade.

Usman et.al. (2021) attempted to capture the asymmetric impact of third-country exchange rate volatility on Pakistan-China commodity trade. The empirical analysis is based on the annual data for 14 industries that export from Pakistan to China and 34 industries that import to Pakistan from China. The empirical findings suggest that the asymmetric assumption alone is not enough, and instead, we should use it along with the third economy effect.

All these studies conducted so far have found out some degree of the third country effect although the researchers had no theoretical foundation as to why they were suspecting 
such an effect. Therefore, this paper develops a theoretical model to demonstrate how the third country effect is transmitted to the bilateral exchange rate.

\section{TWO COUNTRY MODEL FOR FLOATING EXCHANGE RATE DETERMINATION}

Under the floating exchange rate regime, the exchange rate is determined by the demand for and supply of foreign currency. In defining the exchange rate, the price quotation definition (Direct method), i.e., price of one unit of foreign currency in domestic currency, is used in this paper with the following assumptions:

(i) There are only two countries (A and B) producing two goods (X and Y) using two currencies ( $€$ and $\$$ ) whose exchange rate is given by $r$ so that $r . €=\$$.

(ii) Production technology is different in two countries in such a way that Good X is produced in country-A at a lower cost than in country-B and Good $\mathrm{Y}$ is produced in country-B at a lower cost than in country-A. Thus country-A exports its excess supply of $\mathrm{X}$ to country-B and imports $\mathrm{Y}$ from country-B to meet the excess demand. Similarly, country-B exports its excess supply of $Y$ to country-A, and imports $\mathrm{X}$ from country-A to meet its excess demand.

(iii) Demand and supply curves are linear.

(iv) No capital transactions or transfer payments occur between the two countries. The demand for and supply of foreign exchange arises only from trade in goods. Hence, each country's Balance of Payment (BOP) is the same as its Trade Balance (TB).

(v) No transport cost or other charges in exchange of goods, thus the prices between the origin and destination can differ only due to the exchange rate.

(vi) The foreign exchange market adjusts quicker than the goods markets do.

Let us first start with the demand for foreign currency from the viewpoint of country-A. Country-A's excess demand schedule for $\mathrm{Y}$ is the total demand for A's imports, and Country B's excess supply of Y is the total import supply of Country-A.

Mathematical Derivation of Two Country Model for Floating Exchange Rate Determination

\section{A's Demand for foreign currency}

A's Demand for good Y

A's Supply of good Y

A's excess (import) demand for Y

$$
\begin{aligned}
& Q_{y}^{d}=D_{A}-d P_{A y} \\
& Q_{y}^{s}=S_{A}+s P_{A y} \\
& M_{y}^{d}=\left(D_{A}-S_{A}\right)-(d+s) P_{A y} \\
& P_{A y}=\frac{\left(D_{A}-S_{A}\right)}{(d+s)}-\frac{1}{(d+s)} M_{y}^{d}
\end{aligned}
$$


Define,

$$
\begin{gathered}
\frac{\left(D_{A}-S_{A}\right)}{(d+s)}=\alpha_{1} \text { and } \frac{1}{(d+s)}=\beta_{1} \\
P_{A y}=\alpha_{1}-\beta_{1} M_{y}^{d} \quad \ldots \ldots \ldots . . .
\end{gathered}
$$

B's Demand for good Y

$$
Q_{y}^{d}=K_{B}-k P_{B y}
$$

B's Supply of good Y

$$
Q_{y}^{s}=H_{B}+h P_{B y}
$$

B's excess (A's import) supply for Y

$$
M_{y}^{s}=\left(H_{B}-K_{B}\right)+(h+k) P_{B y}
$$

$$
P_{B y}=\frac{\left(H_{B}+K_{B}\right)}{(h+k)}+\frac{1}{(h+k)} M_{y}^{s}
$$

Define,

$$
\begin{aligned}
& \frac{\left(H_{B}+K_{B}\right)}{(h+k)}=\alpha_{2} \text { and } \frac{1}{(h+k)}=\beta_{2} \\
& P_{B y}=\alpha_{2}+\beta_{2} M_{y}^{s} \quad \ldots \ldots \ldots \ldots . .
\end{aligned}
$$

Define exchange rate $=r$,

then $P_{A y}=r P_{B y}$

Multiply Eq. (02) by r to get B's excess (A's import) supply for Y in A's currency

$$
r P_{B y}=r\left(\alpha_{2}+\beta_{2} M_{y}^{s}\right)
$$

As $\quad P_{A y}=r P_{B y}$ and $M_{y}^{s}=M_{y}^{d}$ are in equilibrium, solve Eq. (01) and (03) for $\mathrm{M}_{\mathrm{y}}$, then the volume of imports to country A.

$$
\begin{aligned}
& \alpha_{1}-\beta_{1} M_{y}=r\left(\alpha_{2}+\beta_{2} M_{y}\right) \\
& \alpha_{1}-\beta_{1} M_{y}=r \alpha_{2}+r \beta_{2} M_{y} \\
& M_{y}=\frac{\alpha_{1}-r \alpha_{2}}{\beta_{1}+r \beta_{2}}
\end{aligned}
$$

A's foreign currency demand (D\$) is equivalent to A's import expenditure in B's currency.

$$
D \$=M_{y} \cdot P_{B y}
$$

Substitute Eq. (02) and Eq. (04) into Eq. (05)

$$
\begin{aligned}
D \$ & =M_{y}\left(\alpha_{2}+\beta_{2} M_{y}^{s}\right) \\
D \$ & =\alpha_{2} M_{y}+\beta_{2} M_{y}{ }^{2} \ldots \ldots \ldots \ldots \\
D \$ & =\alpha_{2}\left(\frac{\alpha_{1}-r \alpha_{2}}{\beta_{1}+r \beta_{2}}\right)+\beta_{2}\left(\frac{\alpha_{1}-r \alpha_{2}}{\beta_{1}+r \beta_{2}}\right)^{2}
\end{aligned}
$$




\section{A's Supply of foreign currency}

A's Demand for good X

A's Supply of good X

A's excess (export) supply of X

Define,

$$
\begin{aligned}
Q_{x}^{d} & =G_{A}-g P_{A x} \\
Q_{x}^{S} & =N_{A}+n P_{A x} \\
X_{x}^{S} & =\left(N_{A}-G_{A}\right)+(n+g) P_{A x} \\
P_{A x} & =\frac{\left(N_{A}-G_{A}\right)}{(n+g)}+\frac{1}{(n+g)} X_{x}^{s}
\end{aligned}
$$

$$
\begin{aligned}
& \frac{\left(N_{A}-G_{A}\right)}{(n+g)}=\pi_{1} \text { and } \frac{1}{(n+g)}=\mu_{1} \\
& P_{A x}=\pi_{1}+\mu_{1} X_{x}^{S} \ldots \ldots \ldots \ldots \ldots
\end{aligned}
$$

B's Demand for good X

$$
Q_{x}^{d}=Z_{B}-z P_{B x}
$$

B's Supply of good X

$$
Q_{x}^{s}=V_{B}+v P_{B x}
$$

B's excess (A's export) demand for X

$$
X_{x}^{d}=\left(Z_{B}-V_{B}\right)-(z+v) P_{B x}
$$

$$
P_{B x}=\frac{\left(Z_{B}-V_{B}\right)}{(z+v)}-\frac{1}{(z+v)} X_{x}^{d}
$$

Define,

$$
\begin{aligned}
& \frac{\left(Z_{B}-V_{B}\right)}{(z+v)}=\pi_{2} \text { and } \frac{1}{(z+v)}=\mu_{2} \\
& P_{B x}=\pi_{2}-\mu_{2} X_{x}^{d} \quad \ldots \ldots \ldots .
\end{aligned}
$$

Define exchange rate $=r$,

$$
\text { then } P_{A x}=r P_{B x}
$$

Multiply Eq. (09) by $r$ to get B's excess (A's export) demand for X in A's currency.

$$
r P_{B x}=r\left(\pi_{2}-\mu_{2} X_{x}^{d}\right)
$$

As $P_{A x}=r P_{B x}$ and $X_{x}^{d}=X_{x}^{s}$ are in equilibrium, solve Eq. (08) and (10) for $\mathrm{X}_{\mathrm{x}}$ the volume of export from country A.

$$
\begin{aligned}
& \pi_{1}+\mu_{1} X_{x}^{s}=r\left(\pi_{2}-\mu_{2} X_{x}^{d}\right) \\
& \pi_{1}+\mu_{1} X_{x}=r \pi_{2}-r \mu_{2} X_{x} \\
& X_{x}=\frac{r \pi_{2}-\pi_{1}}{\mu_{1}+r \mu_{2}} \quad \ldots \ldots \ldots \ldots \ldots
\end{aligned}
$$

A's foreign currency supply (S\$) is equivalent to A's export earnings in B's currency.

$$
S \$=X_{x} . P_{B x}
$$


Substitute Eq. (09) and Eq. (11) into Eq. (12)

$$
\begin{aligned}
& S \$=X_{x}\left(\pi_{2}-\mu_{2} X_{x}^{d}\right) \\
& S \$=\pi_{2} X_{x}-\mu_{2} X_{x}{ }^{2} \ldots \ldots \ldots \ldots \ldots . \\
& S \$=\pi_{2}\left(\frac{r \pi_{2}-\pi_{1}}{\mu_{1}+r \mu_{2}}\right)-\mu_{2}\left(\frac{r \pi_{2}-\pi_{1}}{\mu_{1}+r \mu_{2}}\right)^{2} \ldots
\end{aligned}
$$

Equilibrium exchange rate and foreign exchange volume will be determined by the intersection of demand Eq. (07) and supply Eq. (14) in the foreign exchange market.

$$
D \$=S \$
$$

$$
\alpha_{2}\left(\frac{\alpha_{1}-r \alpha_{2}}{\beta_{1}+r \beta_{2}}\right)+\beta_{2}\left(\frac{\alpha_{1}-r \alpha_{2}}{\beta_{1}+r \beta_{2}}\right)^{2}=\pi_{2}\left(\frac{r \pi_{2}-\pi_{1}}{\mu_{1}+r \mu_{2}}\right)-\mu_{2}\left(\frac{r \pi_{2}-\pi_{1}}{\mu_{1}+r \mu_{2}}\right)^{2}
$$

Eq. (16) could be solved for $\mathrm{r}^{*}$, subject to $r>0$ which is the equilibrium exchange rate between A's currency and B's currency.

$$
\alpha_{2}\left(\frac{\alpha_{1}-r^{*} \alpha_{2}}{\beta_{1}+r^{*} \beta_{2}}\right)+\beta_{2}\left(\frac{\alpha_{1}-r^{*} \alpha_{2}}{\beta_{1}+r^{*} \beta_{2}}\right)^{2}=\pi_{2}\left(\frac{r^{*} \pi_{2}-\pi_{1}}{\mu_{1}+r^{*} \mu_{2}}\right)-\mu_{2}\left(\frac{r^{*} \pi_{2}-\pi_{1}}{\mu_{1}+r^{*} \mu_{2}}\right)^{2}
$$

At any exchange rate below the equilibrium rate, there would be excess demand for foreign currency meaning that the country encounters a balance of trade deficit. On the contrary, at any exchange rate above the equilibrium rate, an excess supply of foreign currency means that the country encounters a balance of trade surplus. Under the floating exchange rate regime, it is only at the equilibrium exchange rate the trade balance reaches zero. Theoretically, the floating exchange rate system has a natural tendency to bring the country's trade balance back to equilibrium when disturbed by any temporary shock, given Marshall-Lerner condition ${ }^{1}$ is satisfied.

This simple model can be used to understand how the trade balance is restored through the exchange rate adjustment in response to an exogenous shock. Given all markets are initially are in equilibrium, suppose Country-A, for some reason shuts down a large number of industrial zones where the import of $\mathrm{Y}$ had been used as a raw material. This would cause to fall A's import demand for Y resulting in lower import price and lesser volume. It would be reflected as an inward shift in A's foreign exchange demand curve. Then the exchange rate starts falling (appreciating A's currency). Following exchange rate appreciation, A's currency denominated B's export supply curve too starts shifting downwards. Again, this will bring about further changes to the equilibrium in A's import market resulting in corresponding changes in foreign exchange volume demanded.

\footnotetext{
${ }^{1}$ The Marshall-Lerner condition (after Alfred Marshall and Abba P. Lerner) is satisfied if the absolute sum of a country's export and import demand elasticities is greater than one.
} 
Meanwhile, following the falling exchange rate (A's currency appreciation), A's currency denominated B's demand function for A's exports must shift downwards resulting in lower export price and lower volume for A's exports. This would be reflected as a decline in the volume of foreign exchange supplied.

When all three markets (export, import and foreign exchange market) have fully adjusted, Country-A would have arrived at zero trade balance once again but at a lower exchange rate than before. (A's currency appreciated).

In this way, any given shock to demand or supply functions of the goods markets in the two countries would ultimately alter the exchange rate, maintaining the trade balance zero under the floating exchange rate system. It also implies any rigidity or incompleteness in the exchange rate adjustment process would keep the trade balance in a disequilibrium position.

\section{THIRD COUNTRY EFFECT OF FLOATING EXCHANGE RATE DETERMINATION}

Up to now, we reproduced the traditional standard two country model for floating exchange rate determination. In this section, we focus on the novel concept of the third country effect on exchange rate.

\section{Theorem:}

(a) The bilateral exchange rate between a pair of countries is not essentially determined by foreign exchange transactions between the two countries concerned, but inevitably by the shocks emerging from third party countries.

(b) The third country effect disables the automatic mechanism of a free-floating exchange rate driving the Balance of Trade to a zero balance although the Marshall Lerner condition is satisfied.

\section{Assumptions}

(i) There are only three countries in the world (A, B, C) producing three goods (X, $Y, Z)$ and using three different currencies $(€, \$, ¥)$ respectively.

(ii) The supply and demand curves of all goods market are linear.

(iii) All three countries produce all three goods but specialized production of only one good and export to other two countries.

(iv) The export supply curve of each country is perfectly elastic meaning that export price remains unchanged.

(v) Marshall Lerner condition is satisfied. $\varepsilon_{x}+\varepsilon_{m}>1$

(vi) All countries follow free floating exchange rate regimes. 
(vii) Each country imports one product each from the other two countries and import demand for each good is equivalent to the excess demand in the domestic market for that good/ for the particular good.

(viii) No capital movements between countries in terms of FDI, loans grants or transfers. Nevertheless, foreign currency flows are possible between countries to arbitrage $^{2}$ against exchange rate differentials.

(ix) The foreign exchange market clears faster than the goods market.

(x) No transport cost/taxes involved in the goods market and no transaction cost in foreign exchange markets.

To establish this theorem, we need several building blocks. Figure 1 depicts the nominal exchange rate between two currencies, namely $€$ and $\$$. The slopes of the rays starting from the origin measures the exchange rate between $€$ and $\$$. For example, every point along the $r^{*}=1$ indicates $€$ and $\$$ will be exchanged on one-to-one basis. Similarly, along $r^{*}=2$ line $€$ and $\$$ will be exchanged two to one basis. Note that $r$ acts as a measuring rod. Every $r^{*}$ line when passes through $r$ line, the number at the intersection point measures the exchange rate (the value of $r^{*}$ ). When $r^{*}$ line pivots counter clockwise, it indicates depreciation of $€$ against $\$$.

\section{Figure 1: Bilateral Exchange Rate}

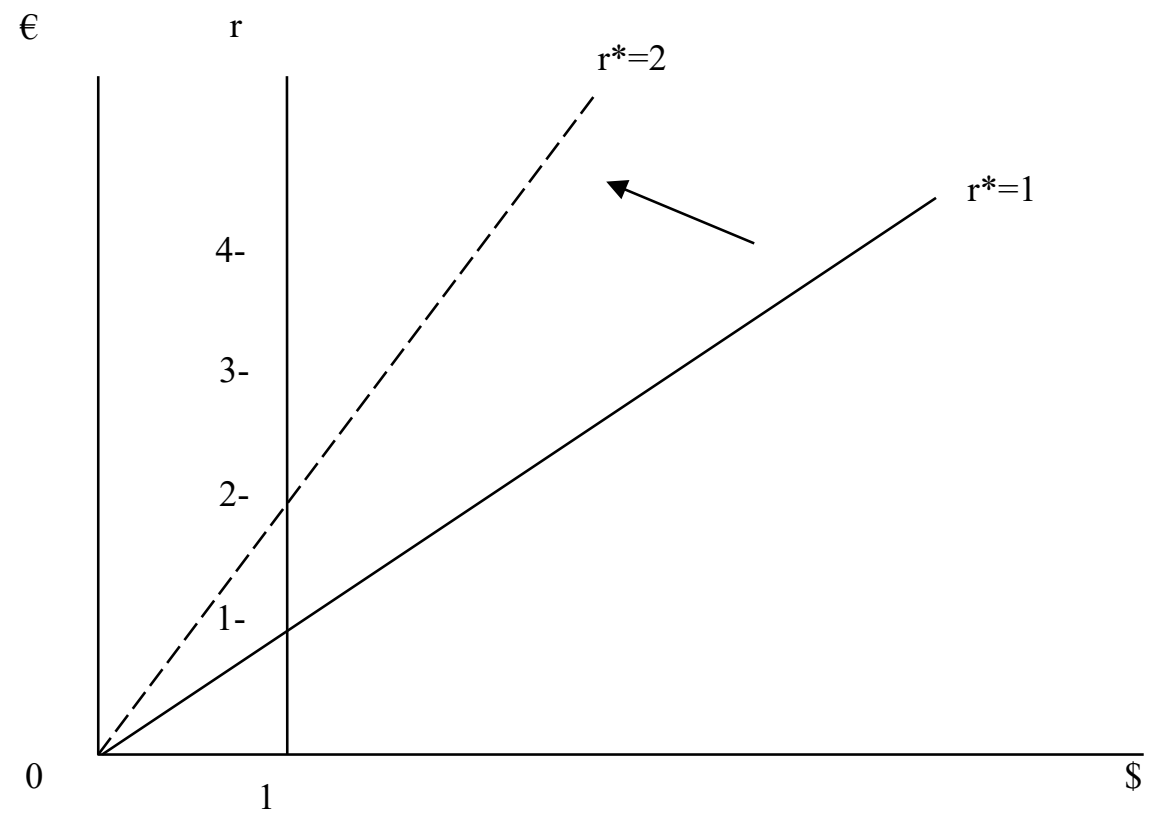

${ }^{2}$ Arbitrage is the simultaneous purchase and sale of the same asset in different markets to profit from tiny differences in the asset's listed price. 
In the foreign currency markets, it is rational to assume that two prices are not possible for a single currency. If there were such a price difference, arbitragers would buy that currency/ the particular currency from low priced market and sell in high priced market. This will guarantee that two prices eventually become equivalent. The maximum possible price difference would be equal to the transaction cost between the two markets. According to our assumptions that no transaction cost is involved, and the foreign exchange market clears faster than the goods market, we can stick to the notion that only one price is possible for one currency. Let us call this concept "Universal Exchange Rate Parity" (UERP) ${ }^{3}$ for convenience. Simply UERP implies exchange rates are determined in a harmonized system and there is no opportunity for arbitrage when UERP is preserved. For example, if $\$=2 €$ and $\$=2 ¥$, then it must hold that $€=¥$. No other exchange rate between $€$ and $¥$ is possible.

In this study, we introduce a simple diagram (See Figure 2) to easily establish UERP in three country model. Suppose A, B, C countries use $€, \$$ and $¥$ as their domestic currencies respectively. We may draw a cross diagram with four quadrants and fix Figure 1 into the right-hand upper quadrant straightaway depicting the exchange rate between $€$ and $\$$. Similarly, two other quadrants can be arranged to depict exchange rates between $\$$ vs. $¥$ and $€$ vs. $¥$. We use the vacant quadrant for $€$ vs. $€$ rate which is a dummy exchange rate moving only along $45^{\circ}$ line, because $r^{*}=1$ by default.

\section{Figure 2: A Harmonized System of Exchange Rates}

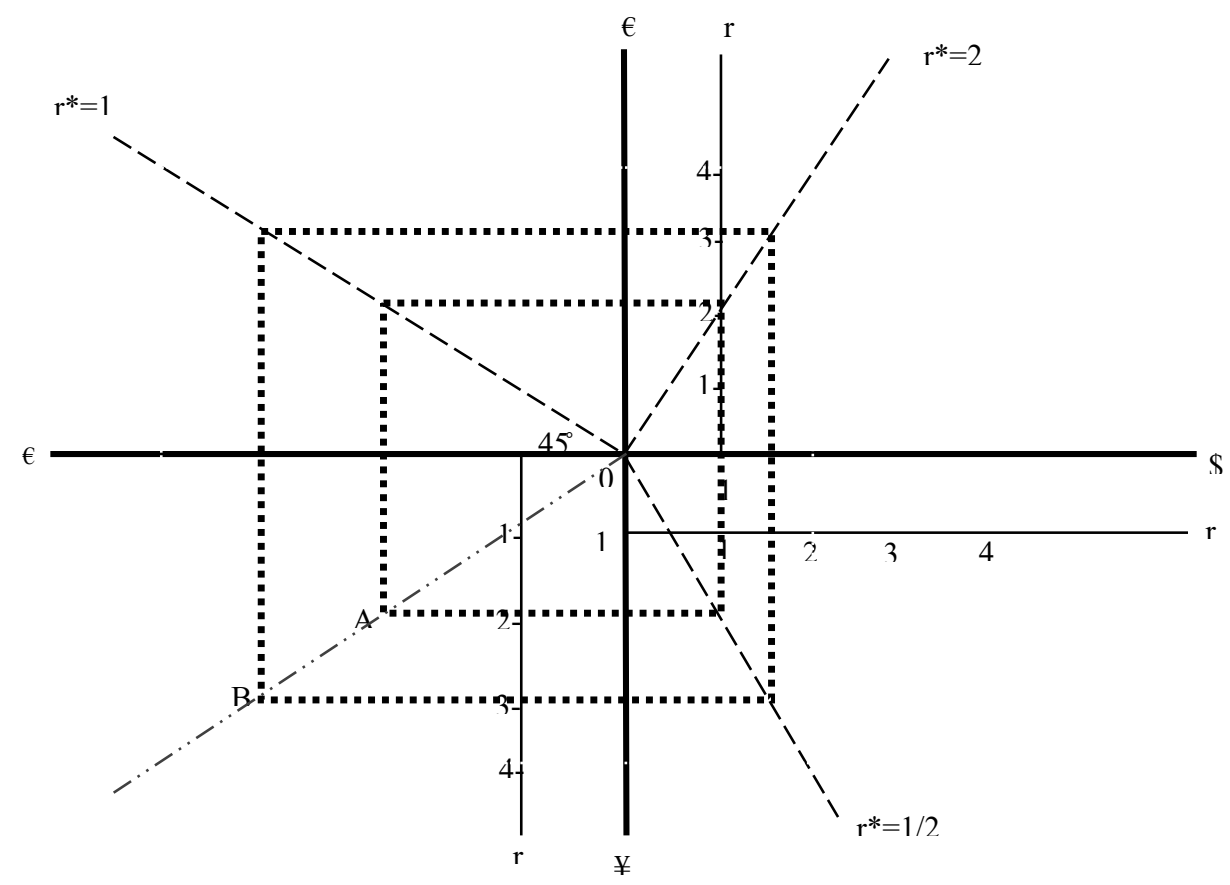

${ }^{3}$ This is the first time that this term is used in a scholarly work. 
The above diagram can be effectively used to establish UERP among three currencies. Assume that $\$=2 €$ and $\$=2 ¥$ and $€=€$ by default. Let us establish these three exchange rates in the right-hand upper quadrant, right hand lower quadrant and the left-hand upper quadrant respectively, as shown by dashed lines. According to UERP, if $\$=2 €$ and $\$=2 ¥$, then the exchange rate between $¥$ and $€$ residually determined and must necessarily be equivalent to $¥=€$. Suppose we do not compute the exchange rate between $¥$ and $€$ and therefore these are not known. Instead, we draw a rectangle of any scale connecting the three exchange rate lines already established, in such a way that each exchange rate line passes through a vertex of the rectangle. Once three of four vertices are pinned down to three exchange rate lines, the remaining vertex must lie somewhere in the left-hand lower quadrant. (A and $\mathrm{B}$ are such vertex points resulting from two rectangles drawn accordingly) A straight line connecting such a vertex point to the origin would yield the exchange rate between $¥$ and $€$, which is $1: 1$ in this case.

The system of exchange rates is harmonized only when all the exchange rate lines pass through the vertices of the rectangle. In case the rectangular shape is incomplete or diverging away, it indicates that UERP is violated and avenues for arbitrage are open. (See Figure 3)

\section{Figure 3: A Disharmonized System of Exchange Rates}

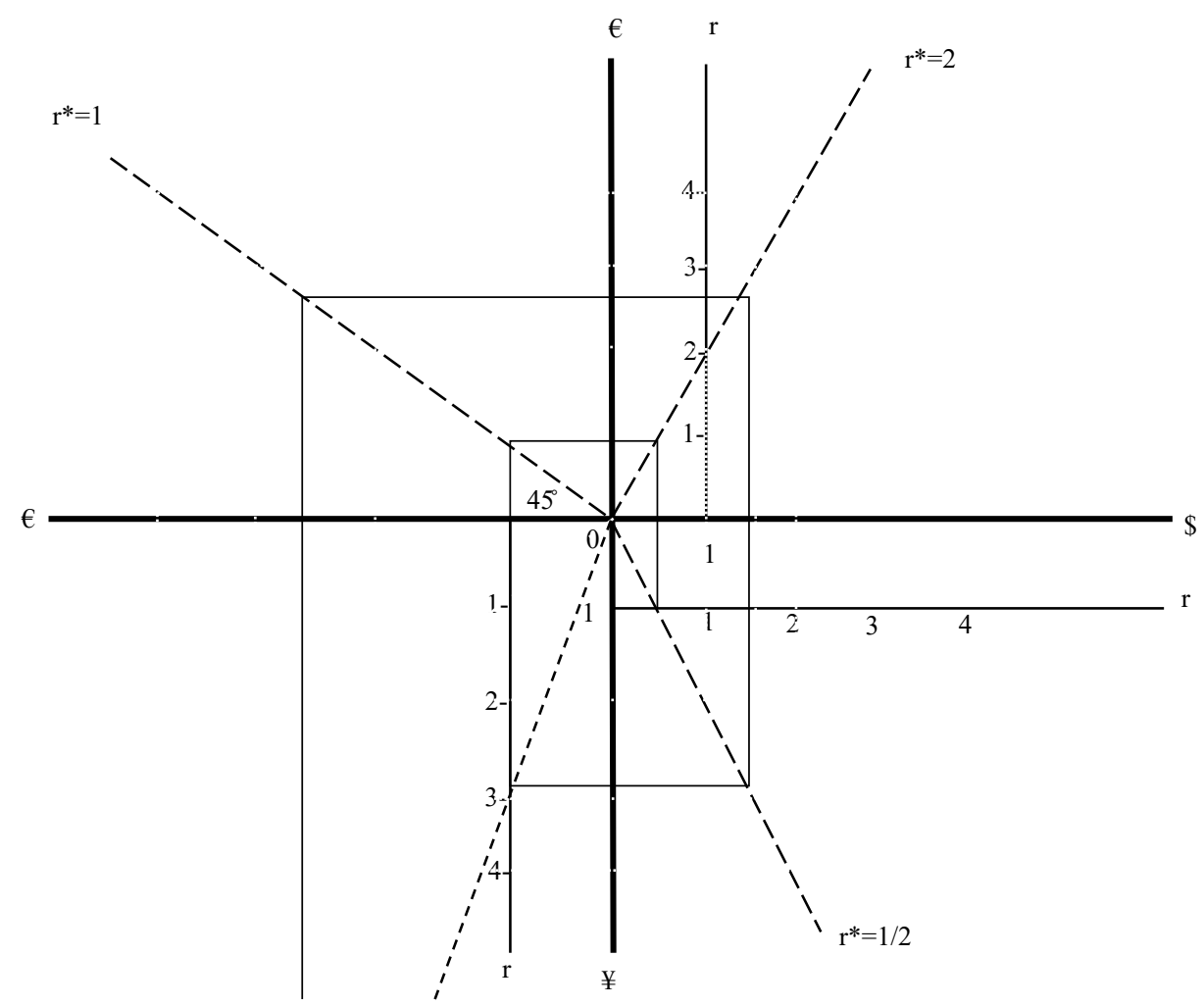


We can draw two important conclusions from UERP concept discussed above.

(a) Given the three currencies, there must be three exchange rates among them. We can fix a maximum of two exchange rates; the remainder must be residually determined by UERP. More generally, if $n$ number of currencies is used in the world, as given by the formula for combinations of two, there must be $C_{2}^{n}=$ $\frac{n !}{2 !(n-2) !}$ number of exchange rates. One can fix the maximum $(n-1)$ number of exchange rates and $C_{2}^{n}-(n-1)$ number of exchange rates is residually determined by UERP. For example, if there are 5 currencies in the world, there must be 10 exchange rates. ${ }^{4}$ One can fix 4 exchange rates the maximum, but the remaining 6 rates are residually determined by UERP.

(b) Given the three currencies, there must be three exchange rates. Then, if one exchange rate has deviated from the initial parity for some reason, at least one of the other two rates must be changed simultaneously. More generally, if $n$ number of currencies are used in the world, there must be $C_{2}^{n}=\frac{n !}{2 !(n-2) !}$ number of exchange rates. If one exchange rate is changed for some reason, at least another $(n-2)$ number of exchange rates need changing to reestablish UERP. For example, if there are five currencies in the world, there must be 10 exchange rates. If one exchange rate is changed for some reason, at least a minimum of three other exchange rates must follow this change simultaneously.

As there are three countries in our model, there are three bilateral trade relationships namely; AB, AC, BC. We apply the two-country model for exchange rate determination developed in section 2 with slight modification to accommodate assumption 4 above. We shall first modify the two-country model $\mathrm{AB}$ and then replicate same to $\mathrm{BC}$ and $\mathrm{AC}$.

\section{A's demand for foreign currency}

A's excess (import) demand for Y

$$
P_{A y}=\alpha_{1}-\beta_{1} M_{y}^{d}
$$

B's (A's import) supply for Y

$$
P_{B y}=\alpha_{2}
$$

Define exchange rate $=\mathrm{r}_{1}$

$$
\text { then } P_{A y}=r_{1} P_{B y}
$$

Multiply Eq. (18) by r to get B's excess (A's import) supply for Y in A's currency.

$$
r_{1} P_{B y}=r_{1} \alpha_{2}
$$

\footnotetext{
${ }^{4} C_{2}^{5}=\frac{5 !}{2 !(5-2) !}=\frac{5 !}{2 !(3) !}=\frac{5 \times 4 \times 3 !}{2 \times 1 \times 3 !}=\frac{20}{2}=10$
} 
As $P_{A y}=r_{1} P_{B y}$ is in equilibrium, solve Eq. (17) and (19) for $\mathrm{M}_{\mathrm{y}}$, the volume of imports to country A.

$$
\begin{aligned}
& \alpha_{1}-\beta_{1} M_{y}=r_{1} \alpha_{2} \\
& \beta_{1} M_{y}=\alpha_{1}-r_{1} \alpha_{2} \\
& M_{y}=\frac{\alpha_{1}-r_{1} \alpha_{2}}{\beta_{1}}
\end{aligned}
$$

A's foreign currency demand (D\$) is equivalent to A's import expenditure in B's currency.

$$
D \$=M_{y} . P_{B y}
$$

Substitute Eq. (18) and Eq. (20) into Eq. (21).

$$
\begin{aligned}
& D \$=M_{y}\left(\alpha_{2}\right) \\
& D \$=\alpha_{2}\left(\frac{\alpha_{1}-r_{1} \alpha_{2}}{\beta_{1}}\right) . \\
& D \$=\frac{\alpha_{1} \alpha_{2}-r_{1} \alpha_{2}^{2}}{\beta_{1}}
\end{aligned}
$$

\section{A's Supply of foreign currency}

A's Supply of good X

$$
\begin{aligned}
P_{A x} & =\pi_{1} \ldots \ldots \ldots \ldots \ldots \ldots \\
P_{B x} & =\pi_{2}-\mu_{2} X_{x}^{d} \ldots \ldots \ldots \ldots
\end{aligned}
$$

Define exchange rate $=r_{1}$

then $P_{A x}=r_{1} P_{B x}$

Multiply Eq. (25) by r to get B's excess (A's export) demand for X in A's currency

$$
r_{1} P_{B x}=r_{1}\left(\pi_{2}-\mu_{2} X_{x}^{d}\right)
$$

As $P_{A x}=r_{1} P_{B x}$ is in equilibrium, solve Eq. (24) and (26) for $\mathrm{X}_{\mathrm{x}}$, the volume of export from country A.

$$
\begin{aligned}
& \pi_{1}=r_{1}\left(\pi_{2}-\mu_{2} X_{x}^{d}\right) \\
& \pi_{1}=r_{1} \pi_{2}-r_{1} \mu_{2} X_{x} \\
& X_{x}=\frac{r_{1} \pi_{2}-\pi_{1}}{r_{1} \mu_{2}}
\end{aligned}
$$

A's foreign currency supply (S\$) is equivalent to A's export earnings in B's currency

$$
S \$=X_{x} \cdot P_{B x}
$$


Substitute Eq. (25) and Eq. (27) into Eq. (28).

$$
\begin{aligned}
& S \$=X_{x}\left(\pi_{2}-\mu_{2} X_{x}^{d}\right) \\
& S \$=\pi_{2} X_{x}-\mu_{2} X_{x}^{2} \\
& S \$=\pi_{2}\left(\frac{r_{1} \pi_{2}-\pi_{1}}{r_{1} \mu_{2}}\right)-\mu_{2}\left(\frac{r_{1} \pi_{2}-\pi_{1}}{r_{1} \mu_{2}}\right)^{2} \ldots(29) \\
& S \$=\pi_{2}\left(\frac{\pi_{2}}{\mu_{2}}-\frac{\pi_{1}}{r_{1} \mu_{2}}\right)-\mu_{2}\left(\frac{\pi_{2}}{\mu_{2}}-\frac{\pi_{1}}{r_{1} \mu_{2}}\right)^{2}
\end{aligned}
$$

\section{Equilibrium in the foreign exchange market}

The equilibrium exchange rate and the foreign exchange volume will be determined by the intersection of demand Eq. (22) and supply Eq. (30) in the foreign exchange market.

$$
\begin{array}{r}
D \$=S \$ \\
\alpha_{2}\left(\frac{\alpha_{1}-r_{1} \alpha_{2}}{\beta_{1}}\right)=\pi_{2}\left(\frac{\pi_{2}}{\mu_{2}}-\frac{\pi_{1}}{r_{1} \mu_{2}}\right)-\mu_{2}\left(\frac{\pi_{2}}{\mu_{2}}-\frac{\pi_{1}}{r_{1} \mu_{2}}\right)^{2} \ldots \ldots \ldots \ldots
\end{array}
$$

Eq. (32) could be solved for $r_{1} *$ subject to $r>0$ which is the equilibrium exchange rate. Accordingly, Eq. (33) demonstrates the foreign exchange market between Country-A and B (i.e., $€$ vs. \$).

$\alpha_{2}\left(\frac{\alpha_{1}-r_{1}^{*} \alpha_{2}}{\beta_{1}}\right)=\pi_{2}\left(\frac{\pi_{2}}{\mu_{2}}-\frac{\pi_{1}}{r_{1}^{*} \mu_{2}}\right)-\mu_{2}\left(\frac{\pi_{2}}{\mu_{2}}-\frac{\pi_{1}}{r_{1}^{*} \mu_{2}}\right)^{2}$

Accordingly, $r_{1}^{*}=f\left(\alpha_{1}, \alpha_{2}, \beta_{1}, \pi_{1}, \pi_{2}, \mu_{2}\right)$, where,

$r_{1}^{*}$ - equilibrium exchange rate (price of $\$$ in terms of $€$ )

$\alpha_{1}$ - intercept of the A's import demand curve for Good-Y

$\alpha_{2}$ - intercept of the A's import supply curve for Good-Y (foreign price in perfectly elastic case)

$\beta_{1}$ - slope of A's import demand curve for Good-Y

$\pi_{1}$ - intercept of the A's export supply curve for Good-X (domestic price in perfectly elastic case)

$\pi_{2}$ - intercept of the A's export demand curve for Good-X

$\mu_{2}$ - slope of A's export demand curve for Good-X

Eq. (33) represents the foreign exchange market between Country-A and B (i.e. $€$ vs. \$). Analogous to this, nothing prevents us from replicating Eq. (33) to represent the foreign exchange market between Country-B and C (i.e., \$ vs. $¥)$ and the foreign exchange market between Country-A and C (i.e. $€$ vs. $¥)$ as follows. 
Accordingly, Eq. (34) demonstrates the foreign exchange market between Country-B and C (i.e. \$ vs. $¥)$

$\rho_{2}\left(\frac{\rho_{1}-r_{2}^{*} \rho_{2}}{\vartheta_{1}}\right)=\omega_{2}\left(\frac{\omega_{2}}{\varphi_{2}}-\frac{\alpha_{2}}{r_{2}^{*} \varphi_{2}}\right)-\varphi_{2}\left(\frac{\omega_{2}}{\varphi_{2}}-\frac{\alpha_{2}}{r_{2}^{*} \varphi_{2}}\right)^{2}$

Accordingly, $r_{2}^{*}=f\left(\rho_{1}, \rho_{2}, \vartheta_{1}, \alpha_{2}, \omega_{2}, \varphi_{2}\right)$, where,

$r_{2}^{*}$ - equilibrium exchange rate (price of $¥$ in terms of $\$$ )

$\rho_{1}$ - intercept of the B's import demand curve for Good-Z

$\rho_{2}$ - intercept of the B's import supply curve for Good-Z (foreign price in perfectly elastic case)

$\vartheta_{1}$ - slope of B's import demand curve for Good-Z

$\alpha_{2}$ - intercept of the B's export supply curve for Good-Y (domestic price in perfectly elastic case)

$\omega_{2}$ - intercept of the B's export demand curve for Good-Y

$\varphi_{2}$ - slope of B's export demand curve for Good-Y

Analogously, Eq. (35) demonstrates the foreign exchange market between Country-C and A (i.e. $¥$ vs. $€)$.

$\pi_{1}\left(\frac{\theta_{1}-r_{3}^{*} \pi_{1}}{\tau_{1}}\right)=\gamma_{2}\left(\frac{\gamma_{2}}{\lambda_{2}}-\frac{\rho_{2}}{r_{3}^{*} \lambda_{2}}\right)-\lambda_{2}\left(\frac{\gamma_{2}}{\lambda_{2}}-\frac{\rho_{2}}{r_{3}^{*} \lambda_{2}}\right)^{2}$

Accordingly, $r_{3}^{*}=f\left(\theta_{1}, \pi_{1}, \tau_{1}, \rho_{2}, \gamma_{2}, \lambda_{2}\right)$, where,

$r_{3}^{*}$ - equilibrium exchange rate (price of $€$ in terms of $¥$ )

$\theta_{1}$ - intercept of the C's import demand curve for Good-X

$\pi_{1}$ - intercept of the C's import supply curve for Good-X (foreign price in perfectly elastic case)

$\tau_{1}$ - slope of C's import demand curve for Good-X

$\rho_{2}$ - intercept of the C's export supply curve for Good-Z (domestic price in perfectly elastic case)

$\gamma_{2}$ - intercept of the C's export demand curve for Good-Z

$\lambda_{2}$ - slope of C's export demand curve for Good-Z

We have developed three equations (Eq. 33, Eq. 34, and Eq. 35) to represent the three bilateral exchange rates namely, $€$ vs. $\$$ in $\mathrm{AB}$ market, $\$$ vs. $¥$ in $\mathrm{BC}$ market, and $€$ vs. $¥$ in $\mathrm{AC}$ market. Now assume all the exchange markets are in equilibrium with the initial exchange rate $€=\$=¥$. This means $r_{1}^{*}=r_{2}^{*}=r_{3}^{*}=1$. We update UERP diagram with this 
new set of information and use it as the starting point to elaborate the "third country effect".

Figure 4 shows UERP in the centre and the respective exchange markets through which those exchange rates are determined. The foreign exchange market between Country $\mathrm{A}$ and $\mathrm{B}(€$ vs. $\$$ ) is shown in the right-hand upper corner.

Figure 4: UERP for Three Exchange Markets

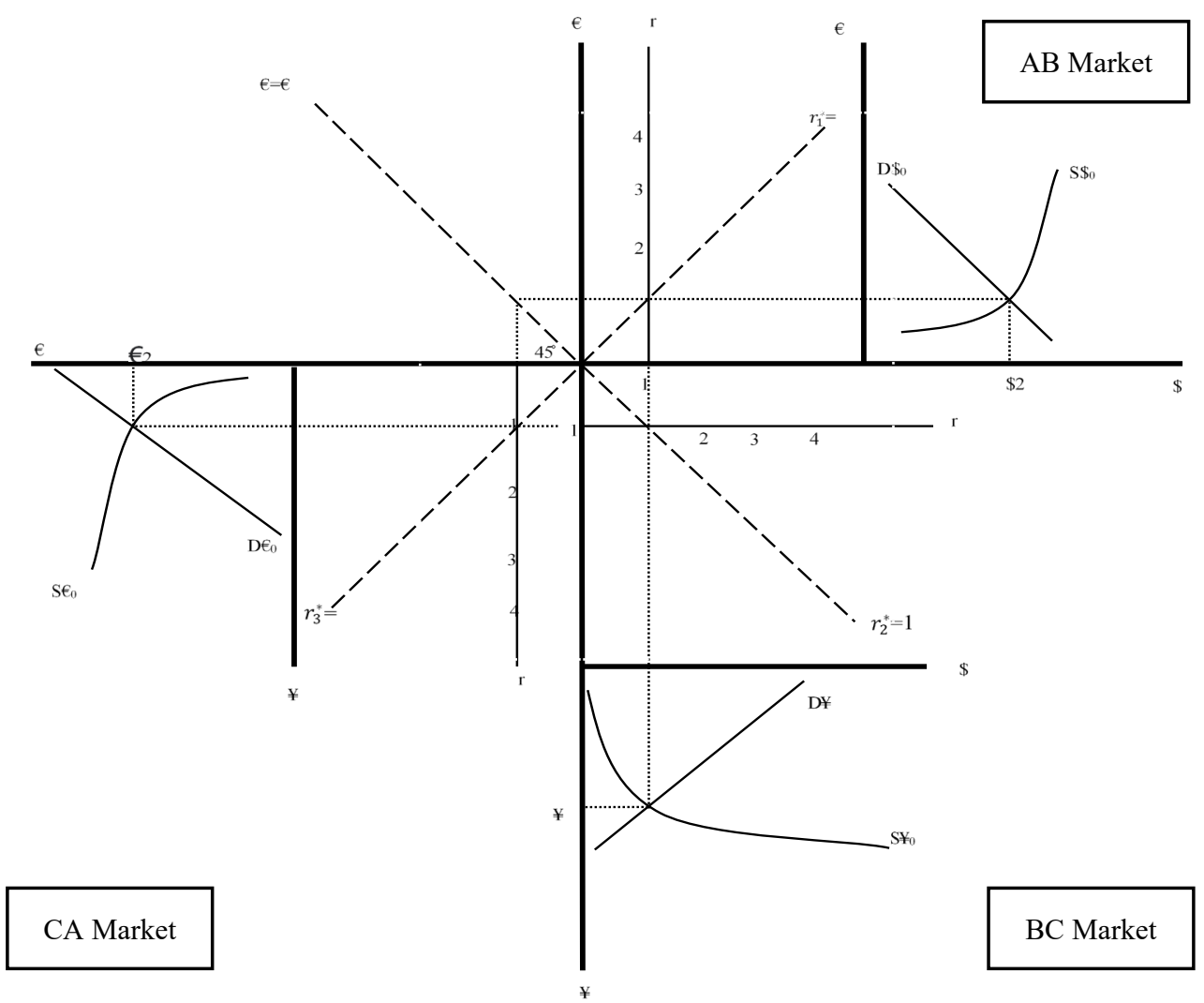

The equilibrium exchange rate determined by market supply and demand in $\mathrm{AB}$ market which is $€=\$$ has been projected to the centre of UERP diagram as $r_{1}^{*}=1$. Similarly, we have established the foreign exchange market for BC market (\$ vs. $¥$ ) and AC market ( $¥$ vs. $€$ ) in the right-hand lower quadrant and the left-hand lower quadrant respectively. This diagram works in such a way that a given shock to the demand or supply curves in one market will be transmitted to at least one of the two other markets to restore UERP.

Starting from an equilibrium position of $r_{1}^{*}=r_{2}^{*}=r_{3}^{*}$ where the initial exchange rate is assumed to be $€=\$=¥$, now we can give a shock to one market and see the reaction taking place in another market. The former is a third country to the latter. Hence, we may call the reaction taking place in the latter as the "third country effect".

This effect is demonstrated in Figure 5. 
Figure 5: UERP Response to a Supply Shock When One Currency is Pegged ( $€$ is pegged to $¥$ on $1: 1$ basis)

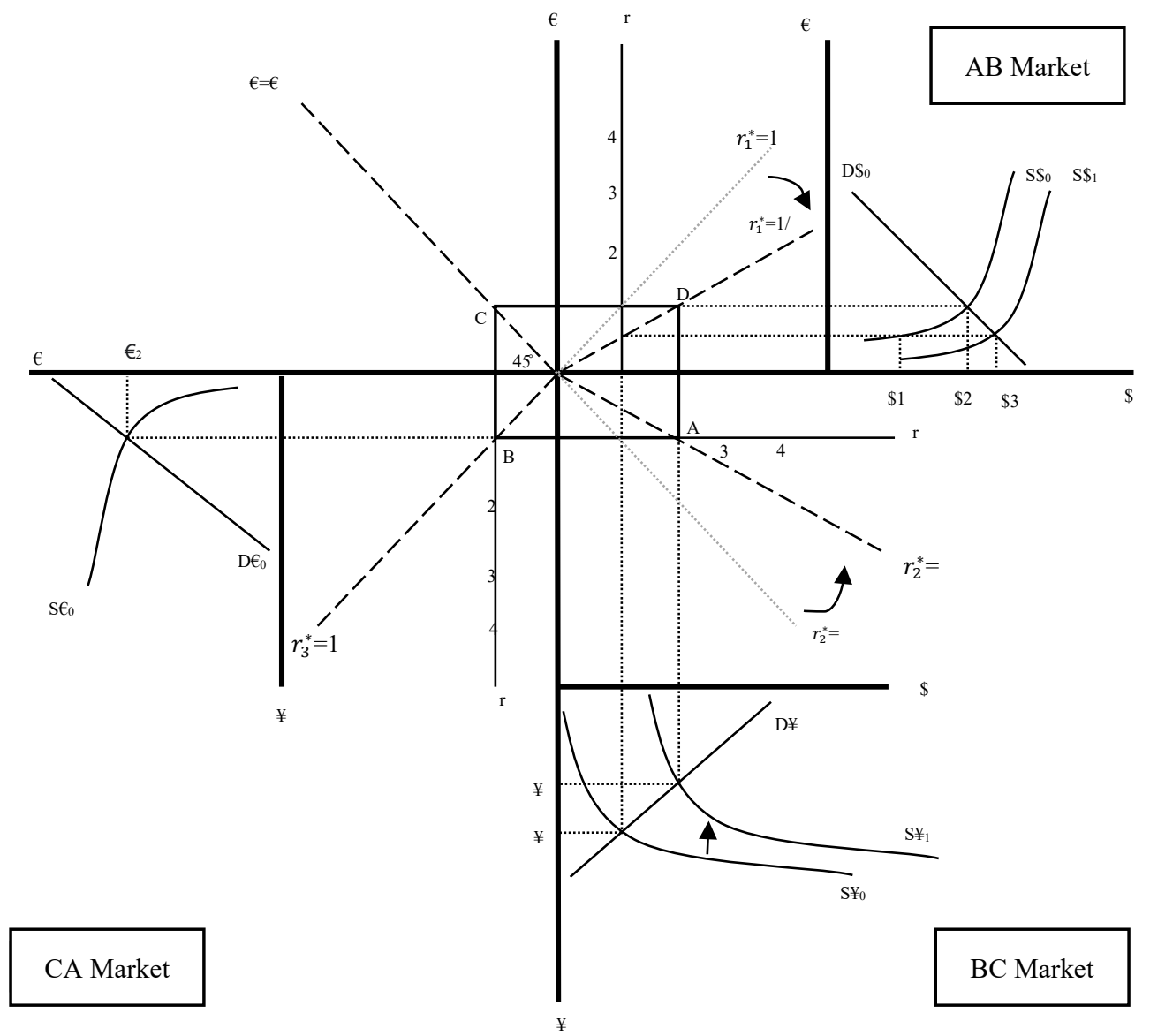

Imagine the Country- $\mathrm{C}$ undergoes an economic recession, and this shock reduces its demand for Good-Y importing from B. This will be reflected as a reduction of B's export income so far received from Country-C in $¥$. Therefore, the supply of $¥$ would fall in the BC market shifting the supply curve from $S ¥_{0}$ to $S ¥_{1}$ as shown in Figure 5. This will appreciate $¥$ against \$. Graphically, the corresponding exchange rate line would pivot counter clockwise from $r_{2}^{*}=1$ to $r_{2}^{*}=2$. Mathematically, the reduction of C's demand for Good-Y from B would be reflected by a diminishing value for $\omega_{2}$, (say $\omega_{@}$ where, $\omega_{@}<\omega_{2}$ ) leading the Eq. (34) into inequality as shown by Eq. (36), given $r_{2}^{*}=1$ remaining unchanged.

$\rho_{2}\left(\frac{\rho_{1}-r_{2}^{*} \rho_{2}}{\vartheta_{1}}\right)>\omega_{@}\left(\frac{\omega_{@}}{\varphi_{2}}-\frac{\alpha_{2}}{r_{2}^{*} \varphi_{2}}\right)-\varphi_{2}\left(\frac{\omega_{@}}{\varphi_{2}}-\frac{\alpha_{2}}{r_{2}^{*} \varphi_{2}}\right)^{2}$

However, the excess demand for $¥$ in the $\mathrm{BC}$ market would raise the price of $¥$ and reestablish equilibrium as stated in Eq. (34) but at a higher exchange rate $r_{2}^{*}=2$ now. 
It is now obvious that the exchange rates $€=\$$ and $€=¥$ are no longer valid when $¥$ raised to $¥=2 \$$. To make the rest of the analysis simple, let us assume $€$ has been pegged to $¥$ on a 1:1 basis. Our intention behind this assumption is to retain at least one exchange rate unchanged. Now $€=¥$ and $¥=2 \$$. Then $€$ must be equal to $2 \$$ under a flexible regime. This happens as a result of arbitrage actions to buy currencies in the low-priced market and sell in the high-priced market. Instead of buying $1 \$$ for $1 €$ in the $\mathrm{AB}$ market, the arbitragers now go to the AC market with $1 €$ and exchange it for $1 ¥$. With that $1 ¥$ they buy $2 \$$ in the $\mathrm{BC}$ market and return to the $\mathrm{AB}$ market where they would realize $2 €$ for $2 \$$ in cash. It is interesting to note that they started with $1 €$ in hand and ended up with $2 €$ in hand. This could happen as long as two prices for \$ are existing in the two markets. When this process continues, it brings an additional $\$$ supply to the $A B$ market which would cause the $\$$ supply curve to gradually shift to the right from $\mathrm{S} \$_{0}$ to $\mathrm{S} \$_{1}$ as shown in the upper right corner of Figure 5. When $\$$ supply curve gradually shifts to the right, the equilibrium exchange rate falls ( $r_{1}^{*}$ line pivots clockwise) and finally settles as $r_{1}^{*}=1 / 2$ when $\$=1 / 2 €$. After the exchange rates are fully adjusted and all three markets have reverted to equilibrium positions, however, it can be seen that $€$ has appreciated against $\$$ eventually in the AB market. Recall that the initial change took place in Country-C and then affected C's trade with B. It is interesting to note that the final outcome is an appreciation of $€$ against $\$$ in $\mathrm{AB}$ market affecting trade between Country- $\mathrm{A}$ and $\mathrm{B}$ which are not directly answerable to the said initial change. If we recall the link between the exchange rate and the import and export demand functions derived earlier, it is not difficult to realize that trading volumes of Good-X and $\mathrm{Y}$ in trade between Country-A and $\mathrm{B}$ must have changed analogously due to this impact transmitted from some other country. We shall call this scenario as the "third country effect of exchange rate".

The reverse of the ML condition suggests that currency appreciation must lead to deterioration in the trade balance which is exactly the case in the AB market now. It is true that $\mathrm{AB}$ market is now in equilibrium because $\$$ demand equals $\$$ supply. However, it does not mean that trade between the two countries is balanced. A careful look into the $\mathrm{AB}$ market will reveal that Country-A is now having a trade deficit equivalent to $\$ 1-\$ 3$ due to the appreciation of $€$. This would be further verified in terms of Eq. (33) which we derived to represent the $\mathrm{AB}$ market. The appreciation of $€$ against $\$$ owing to arbitragers' behaviour (altering $r_{1}^{*}$ from $r_{1}^{*}=1$ to $r_{1}^{*}=1 / 2$ ), would turn the Eq. (33) into an inequality as shown below by Eq. (37), given all else remain unchanged. The economic interpretation is that A's trade balance with B is in deficit now.

$\alpha_{2}\left(\frac{\alpha_{1}-r_{1}^{*} \alpha_{2}}{\beta_{1}}\right)>\pi_{2}\left(\frac{\pi_{2}}{\mu_{2}}-\frac{\pi_{1}}{r_{1}^{*} \mu_{2}}\right)-\mu_{2}\left(\frac{\pi_{2}}{\mu_{2}}-\frac{\pi_{1}}{r_{1}^{*} \mu_{2}}\right)^{2}$

It is crucial to note that the said trade deficit will not be evaporated automatically even under the free-floating system. This is because the $\mathrm{AB}$ market is already in equilibrium and therefore there is no tendency to adjust the exchange rate any longer. It means the "third country effect of exchange rate" could be long lasting. 
Figure 6: UERP Response to a Supply Shock When One Currency is Pegged ( $€$ is pegged to $\$$ on $1: 1$ basis)

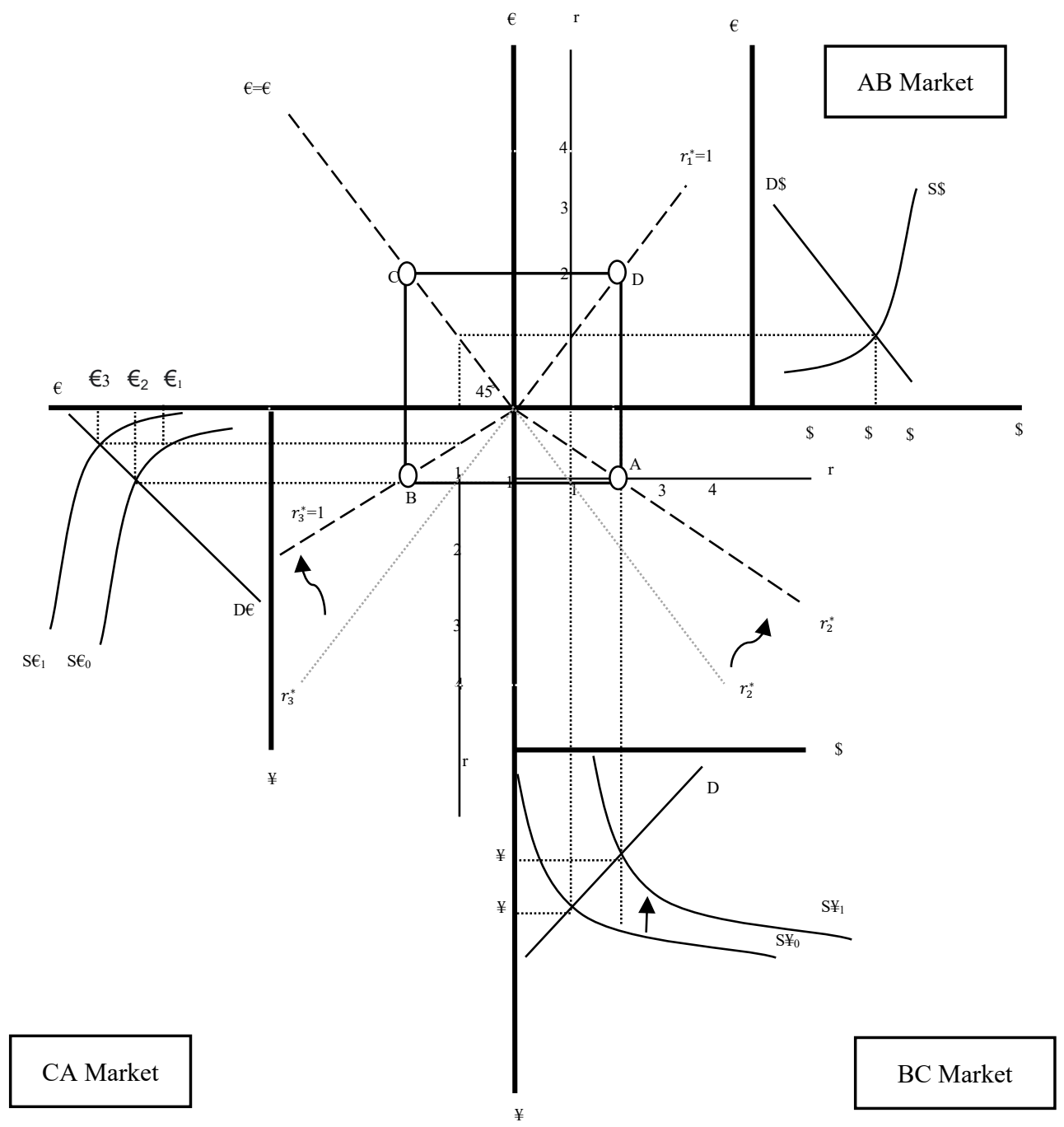

This concept can be further elaborated in Figure 6 above. Instead of our early assumption that $€$ has been pegged to $¥$, now we assume $€$ is pegged to $\$$ on a $1: 1$ basis. Then arbitrages in the AC market would sell $1 ¥$ in the $\mathrm{BC}$ market for $2 \$$ and resell those $2 \$$ in the $\mathrm{AB}$ market for $2 €$. With these $2 €$, they can buy $2 ¥$ after returning to the $\mathrm{AC}$ market. By repeating this practice, they can double their $¥$ money in hand. When this practice is repeated, $€$ supply would increase causing $€$ to depreciate against $¥$ in the AC market as shown in the lower left-hand quadrant in Figure 6. As long as $€=\$$ rate remains unchanged, any divergence in $¥$ vs. $\$$ rate from its original value must ultimately transmit to $€$ vs. $¥$ rate preserve UERP. This is graphically shown by $r_{3}^{*}$ pivoting clockwise in response to the initial change in $r_{2}^{*}$ given $r_{1}^{*}$ remains unchanged. 
This result again leads to our former conclusion that the exchange rate in the $\mathrm{AC}$ market is not necessarily determined by trade between $\mathrm{A}$ and $\mathrm{C}$ but is influenced by the shocks emerging from $\mathrm{BC}$, supporting the argument of the "third country effect". In this case, also the Country- $C$ undergoes a trade deficit equivalent to $€_{1}-€_{3}$ in the CA market, while the $\mathrm{CA}$ exchange market continues to be in equilibrium any longer. It means that there is no automatic mechanism to reverse the "third country effect" even in a free-floating system.

\section{Figure 07: UERP When None of the Currencies is Pegged}

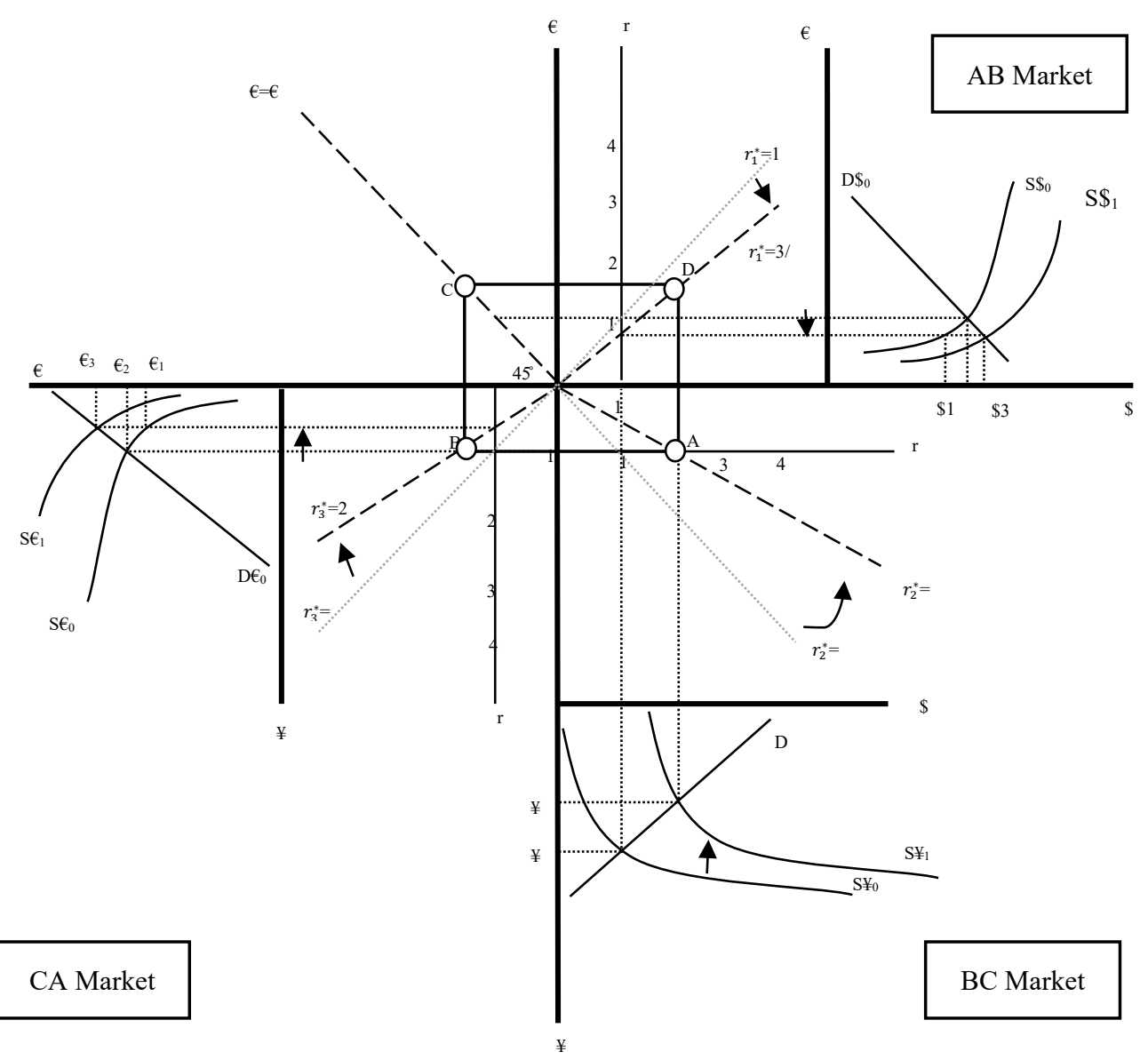

Even though we assumed for the sake of simplicity in the previous two cases, we have no logical reason to assume that at least one exchange rate is pegged. This means that both $\mathrm{AB}$ and $\mathrm{AC}$ markets could simultaneously respond to the initial change in the $\mathrm{BC}$ market as shown in Figure 7 above. More precisely, when $¥$ appreciated in $\mathrm{BC}$ market due to a fundamental trade shock, UERP could be preserved by a combined result of $\$$ being depreciated by a certain per cent against $€$ in $\mathrm{AB}$ market, and $€$ being depreciated by a certain per cent against $¥$ in CA market. 
Consider the numerical example depicted in Figure 7. It shows that starting from the initial exchange rate $€=\$=¥$, if the equilibrium exchange rate in $\mathrm{BC}$ changes to $2 \$=¥$ due to trade shock, then the equilibrium exchange rate in $\mathrm{AC}$ could change to $€=2 / 3 ¥$ when and only when the equilibrium exchange rate in $\mathrm{AB}$ changed to $\$=3 / 4 €$. No matter by how much each rate changes, as long as the equilibrium exchange rates in $\mathrm{AB}$ and $\mathrm{CA}$ markets are affected by a shock arising in the $\mathrm{BC}$ market, it supports the argument of the "third country effect". More interestingly, now it has created one trade deficit for Country-A in favour of B and another deficit for Country-C in favour of A, while there is no deficit or surplus between Country-B and $\mathrm{C}$ where the original shock emerged.

\section{Figure 8: UERP When all Currencies are Free Floating}

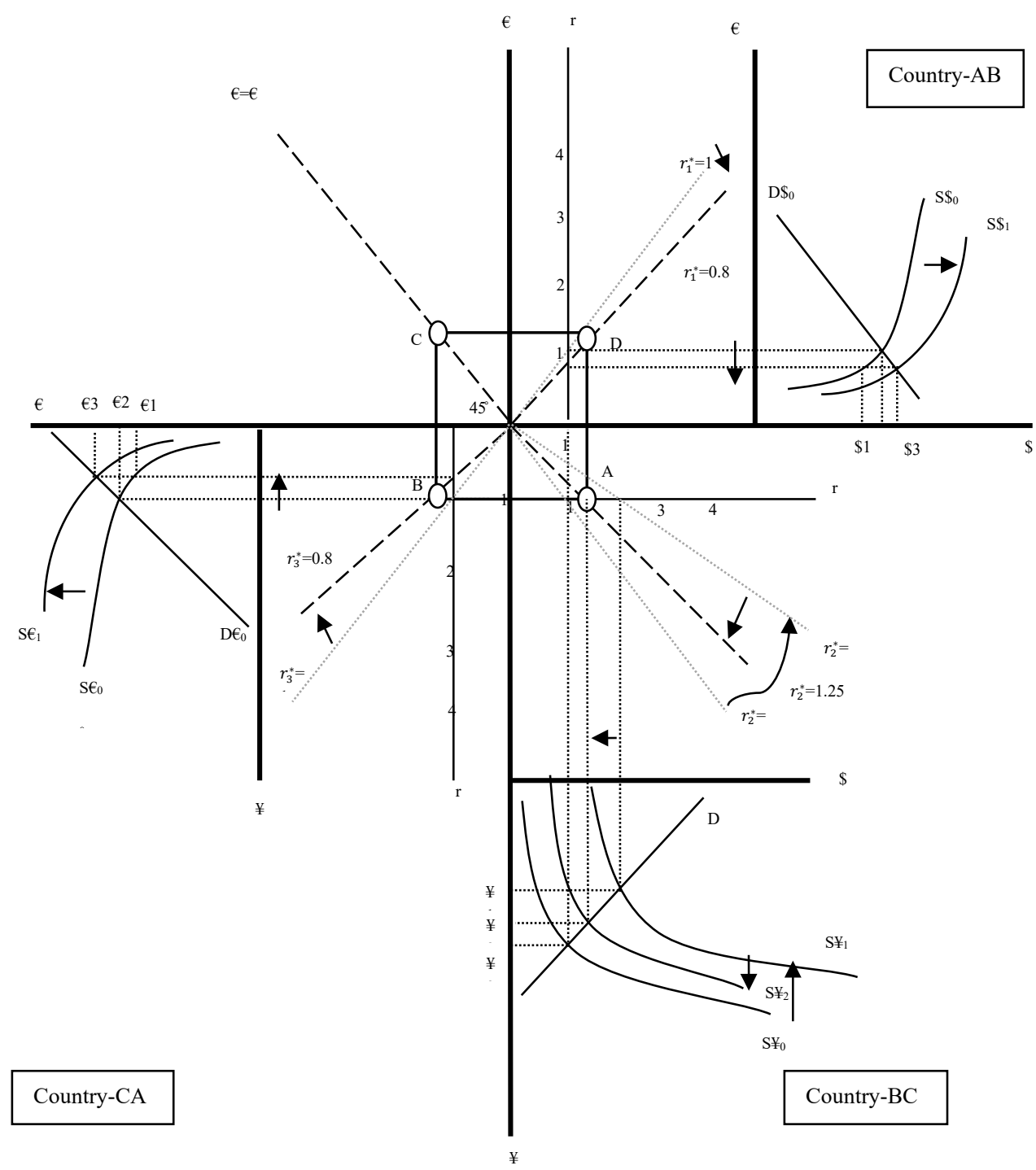


Having discussed the above-mentioned three scenarios, now we can think of a more realistic and more dynamic situation of the third country effect. In the previous cases, we worked on the implied hypothesis that no further changes in the $\$$ vs. $¥$ rate $\llbracket\left(r \rrbracket 2^{\wedge *}\right)$ of the BA market is possible after the initial change. Indeed, this is not the case in a freefloating system. Nothing prevents us from assuming that all three exchange rates are free to change. The analysis of the scenario depicted in Figure 8 above is based on this assumption.

Reconsider the previous example where the Country-C was assumed to have undergone an economic rescission. This would in turn reduce its import demand for Good-Y. This implies a drop in B’s export income hitherto earned from Country-C in $¥$. Therefore, the supply of $¥$ would fall in the BC market shifting the supply curve inward from $S ¥_{0}$ to $S ¥_{1}$ as shown in the right-hand lower quadrant of Figure 8 . This causes $¥$ to appreciate against $\$$. The $r_{2}^{*}$ line pivots counterclockwise from $r_{2}^{*}=1$ to $r_{2}^{*}=2$. The exchange rates $€=\$$ and $€=¥$ would be no longer valid when $¥$ raised to $¥=2 \$$. This means UERP is disturbed now. When UERP is violated, arbitragers would soon begin to buy currencies in the lowpriced market and sell in the high-priced market until the price differences disappear. Instead of buying $1 \$$ for $1 €$ in the $\mathrm{AB}$ market, one might now go to the $\mathrm{AC}$ market with $1 €$ and exchange it for $1 ¥$. With that $1 ¥$ he can buy $2 \$$ in the $B C$ market and return to the $\mathrm{AB}$ market where they would realize $2 €$ for $2 \$$. Recall that he started with $1 €$ in hand and ended up with $2 €$ in hand. This would happen as long as two prices for a single currency are visible in two markets. When arbitrage is allowed, it pumps additional $€$ stock into the CA market, additional ¥ stock into the $\mathrm{BC}$ market, and additional \$ stock into the $\mathrm{AB}$ market. This should shift the supply curve in each market to the right as shown in Figure 8. When all the markets have been fully adjusted and UERP is restored, there would not be any more incentive for arbitrage trading. However, it is exciting to note that none of the markets would reinstate the original exchange rate as $€=\$=¥$. Instead, $\$$ has depreciated in the $\mathrm{AB}$ market, $€$ has depreciated in the $\mathrm{CA}$ market and $¥$ has appreciated in the $\mathrm{BC}$ market but by a lesser amount than it happened in the initial change. Notwithstanding the fact that the initial change in the exchange rate in the $\mathrm{BC}$ market was partly reversed, our conclusion about the third country effect still stands unbeaten. Recall that the initial change took place in Country-C and then affected C's trade with B. However, finally, the impact was transmitted to the exchange rates in the $\mathrm{AB}$ market and CA markets, which are not directly responsible for the said initial change.

It proves our theorem that the bilateral exchange rate between a pair of countries is not essentially determined by the foreign exchange transactions between the two countries concerned, but inevitably by the shocks emerging from third party countries; briefly known as the "third country effect of exchange rate". Moreover, latter has created one trade deficit for Country-A in favour of B and another deficit for Country-C in favour of A. In this case, the exchange rate does not tend to adjust any longer to wipe out trade deficits because all the exchange markets are already in equilibrium. This proves the 
second part of our theorem that the third country effect disables the automatic mechanism of a free-floating exchange rate driving the Balance of Trade to a zero balance when Marshall Lerner condition is satisfied.

\section{SOURCES OF THE THIRD COUNTRY EFFECT}

In the previous example, we considered Country-C as the third country from A's and B's points of view. Also, we recognized a contraction of export demand of Country-B following an economic recession in Country- $\mathrm{C}$ as the initial shock giving birth to the "third country effect". Ultimately, we showed that Country-A and B, which are not answerable for the said economic shock underwent trade deficits due to the "third country effect".

A careful look into the three analogous exchange rate equations given by Eq. (33), Eq. (34) and Eq. (35) would reveal that there are many potential sources for the emergence of the third country effect even in the absence of autonomous capital flows. Some of these are economic fundamentals while the others are likely to be demand and supply shocks.

According to the exchange rate equations given by Eq. (33), Eq. (34) and Eq. (35), we have identified six independent variables determining a bilateral exchange rate as,

$r^{*}=f\left(\alpha_{1}, \alpha_{2}, \beta_{1}, \pi_{1}, \pi_{2}, \mu_{2}\right)$

where,

$r^{*}$ - equilibrium exchange rate

$\alpha_{1}$ - intercept of the import demand curve

$\alpha_{2}$ - intercept of the import supply curve

$\beta_{1}$-slope of the import demand curve

$\pi_{1}$ - intercept of the export supply curve

$\pi_{2}$ - intercept of the export demand curve

$\mu_{2}$ - slope of the export demand curve

Any of those variables is likely to act as an intermediate variable transmitting the third country effect to the exchange rate. A few examples are given in Table 1 below.

Up to this point, we had assumed that there were no capital movements between countries except for arbitrage transactions in the presence of exchange rate differentials. We can add the autonomous capital inflows to the supply side and the autonomous capital outflows to the demand side of the exchange rate equations we have already derived in Eq. (33), Eq. (34) and Eq. (35) without much difficulty. In this study, we define all capital flows which are not dependent on the exchange rate as autonomous. It may include foreign loans, grants, FDI, portfolio investments, capital transfers etc., as long as these 
are not dependent on the exchange rate. Such autonomous capital movements would only act as demand and supply shifters in the foreign exchange markets and therefore could be effectively used to strengthen our argument about the third country effect.

Table 1: Economic Shocks / Economic Fundamentals Creating Third Country Effects

\begin{tabular}{ll}
\hline Economic shock / change in economic fundamentals & $\begin{array}{l}\text { Transmission } \\
\text { variable }\end{array}$ \\
\hline Economic recession (reduction of output / income) & $\alpha_{1}, \alpha_{2}, \pi_{1}, \pi_{2}$ \\
Inflation/ changes in money supply & $\alpha_{2}, \pi_{1}$ \\
Economic embargos / Tariffs / Quotas & $\alpha_{1}, \alpha_{2}, \pi_{1}, \pi_{2}$ \\
Import substitution policies & $\alpha_{1}, \pi_{2}, \beta_{1}, \mu_{2}$ \\
Export promotion policies & $\alpha_{2}, \pi_{1}$ \\
Supply shocks due to bad weather, labour turmoil, power failures, natural & $\alpha_{2}, \pi_{1}$ \\
hazard etc. & $\alpha_{1}, \pi_{2}$, \\
Trade pacts & \\
\hline
\end{tabular}

\section{CONCLUSION}

This paper attempted to develop a theoretical model that explains the third country effect on exchange rate. Although the third country effect on the exchange rate has been a concern in the empirical arena, it has been so far applied through common insights of the researchers without any theoretical foundation. In this setting, this paper contributes to the existing domain of knowledge by introducing a theoretical model that forms the logical base for such empirical studies to be carried out in the future. Future researchers can verify its validity by means of Monte Carlo simulations with artificial data or empirical data.

\section{REFERENCES}

Bahmani, M. \& Aftab, M. (2018). A new perspective on the third-country effect: The case of Malaysia-US industry-level trade. The Journal of International Trade \& Economic Development, 27(6), 607-637.

Bahmani, M. and Bolhassani, M. (2014). Exchange rate uncertainty and trade between U.S. and Canada: Is there evidence of third-country effect?". The International Trade Journal 28(1), 23-44.

Bahmani, M. and Xu, J. (2012). Impact of exchange rate volatility on commodity trade between US and China: Is there a Third-Country Effect. Journal of Economics Finance, 36, 555-586. 
Cushman, D.O. (1986). Has exchange risk depressed international trade; the impact of third country exchange risk. Journal of International Money Finance, 5. 361-379.

Hodrick, R. and Vassalou, M. (2002). Do we need multi-country models to explain exchange rate and interest rate and bond return dynamics? Journal of Economics Dynamics and Control, 26, 1275-1299.

Kimberly, B., and Mark, N. (2015). Third-country effects on the exchange rate. Journal of International Economics, 96, 227-243.

Maggie, X. C. and Joshi, S. (2010). Third-country effects on the formation of free trade agreements. Journal of International Economics, 82, 238-248.

Marsh, I. W. and MacDonald, R. (2004). Currency spillovers and tri-polarity: A simultaneous model of the US Dollar, German Mark and Japanese Yen. Journal of International Money and Finance, 23, 99-111.

Melecky, M. (2008). A structural investigation of third-currency shocks to bilateral exchange rates. International Finance, 11(1), 19-48.

Melecky, M. and Kingston, G. (2007). Currency preferences and Australian Dollar. Journal of International Money and Finance, 23(3), 454-467.

Nucci, F. (2003). Cross-country cross-multi forward exchange premiums as prediction of spot rate changes: Theory and evidence. Journal of Banking and Finance, 27, 183200 .

Usman, A., Apergis, N. \& Anwar, S (2021). Examining the asymmetric effects of thirdcountry exchange rate volatility on Pakistan-China commodity trade. Journal of International Commerce, Economics and Policy, 12 (2), 1-39. 